\title{
Laboratory rearing and life history of an emerging grape pest, Xylotrechus arvicola (Coleoptera: Cerambycidae)
}

\author{
E. García-Ruiz ${ }^{\dagger}$, V. Marco and I. Pérez-Moreno \\ Departamento de Agricultura y Alimentación, Complejo Científico, \\ Tecnológico, ICVV (Universidad de La Rioja, Gobierno de la Rioja, CSIC), \\ Madre de Dios 51, 26006 Logroño, La Rioja, Spain
}

\begin{abstract}
Several aspects of the biology of Xylotrechus arvicola (Olivier), an emerging grape pest, were studied under laboratory conditions. Four diets were tested to rear this species in the laboratory. Among them, only one made rearing from larva to adult possible. The highest mortality, in all cases, was recorded during the first days of larval development. Larvae were kept 45 days at $8^{\circ} \mathrm{C}$ to break diapause in order to reduce the normal field larval developmental time. The species' developmental time was similar between sexes, while pupal developmental time and weight were significantly greater for females than for males. As part of a complementary study, life table parameters of females obtained from the larvae reared on the artificial diet were compared to those of females emerged from field-infested grape root wood. Both laid the majority of eggs in the first two weeks after emergence, and they had a similar pre-laying period. Nevertheless, the females from the diet-reared larvae lived significantly longer, laid eggs over a longer period of time and showed higher fertility than those emerging from infested grape root, suggesting that diet fulfils larval nutritional needs. The species' laboratory-reared population exhibited a low intrinsic growth rate value $\left(r_{\mathrm{m}}=0.01\right)$ as a result of its long egg-to-adult developmental time and its high larval mortality.
\end{abstract}

Keywords: Xylotrechus arvicola, rearing protocol, artificial diet, fecundity, rate of increase

(Accepted 4 July 2011; First published online 6 September 2011)

\section{Introduction}

Xylotrechus arvicola (Olivier) (Coleoptera: Cerambicidae) is a xylophagous species inhabiting dead wood and decaying broadleaf trees in many parts of Europe, West Asia and North Africa (Villiers, 1978). However, in the 1990s, it was

*Author for correspondence

Fax: (+34)-91-3572293

E-mail: esteban.garcia@inia.es

+ Current address: Departamento de Protección Vegetal, Instituto Nacional de Investigación y Tecnología Agraria y Alimentaria (INIA), Crta. de la Coruña km 7.5, 28040 Madrid, Spain recorded in vineyards in La Rioja (Spain) as causing damage to grape stem and branches (Ocete \& Del Tío, 1996). Since then, it has rapidly expanded throughout this and other important wine regions, such as Castilla-La Mancha (Rodríguez et al., 1997), Castilla-León (Moreno, 2005) and Navarre (Ocete et al., 2002) and endangers one of the key crops in Spain covering more than 1.3 million cultivated hectares.

The larvae dig galleries that diminish the plant's capacity to transport sap by reducing the vascular area and allowing fungal spread, resulting in smaller berries, which degrades wine quality by incrementing the proportion of berry skin in overall wine composition. To the best of our knowledge, it has not yet been recorded as a pest in any other part of the world. However, this species could threaten other wine regions inside, or even beyond, its current distribution area. 
Currently, growers do not have efficient control tools against $X$. arvicola, and the available prophylactic measures are insufficient because little is known about the biology of this pest. Adults are active in the field mainly between the end of March and the end of July, with higher population levels at the end of May with higher temperatures. Eggs are laid in the cracks of bark, and recently emerged larvae rapidly penetrate the plant. The number of larval instars is not yet known, but may be variable, as occurs with other species of the same family (Adachi, 1988). Low temperature during the last larval instars' development induces a diapause. After more than a one-year larval growing period, a broader gallery connected to the outside is excavated where larvae moult to pupae. Adults emerge at between 20 and 30 days. Thus, the four developmental stages can occur simultaneously in the field between April and June (Moreno, 2005). Egg-to-adult development in the field normally lasts two years.

In order to develop effective control tools, it is necessary to know the species' biology and ecology. One of the most comprehensive is the intrinsic rate of increase $\left(r_{\mathrm{m}}\right)$, defined as "the capacity of increase of a single organism belonging to a population under some specific physical conditions" (Birch, 1948). It is a good indicator of the fate of a population in a specific environment, and of the potential of this population or species to exploit certain resources. Life tables summarise the most important population characteristics used to estimate this parameter and to determine the effect of diverse factors, such as temperature or host species, on the studied pest species' capacity of increase (Harcourt, 1969). They are used to study the population dynamics of many insect pests (Cornell \& Hawkins, 1995; Naranjo \& Ellsworth, 2005; Toepfer \& Kuhlmann, 2006). A better knowledge of many of these questions can only be acquired by establishing a laboratory colony of X. arvicola. It can be done with the help of artificial diets that allow one to obtain a large number of specimens over a discrete period of time to be used in laboratory bioassays or for ecological, physiological or behavioural studies, thereby being independent of seasonal resources (Singh, 1983). Cerambycids are a very difficult group to rear in the laboratory, mainly because of their high mortality rate during larval instars and their long life cycle (Galford, 1985; Linit, 1985), but many authors have already attempted to rear these species under laboratory conditions for the purpose of easily exploring effective control methods (Dubois et al., 2002; Wang et al., 2002) because some of these are among the most important pests in the world, causing enormous losses in agricultural and forest plant species. Moreno (2005) previously tested different diets for cerambycids with $X$. arvicola, but only the larvae extracted from wood could be reared in the laboratory.

The aim of this study is to develop an artificial diet to rear $X$. arvicola in the laboratory that satisfies the nutritional and metabolic requirements to complete this species' whole life cycle, and to make rearing easier and independent of natural stationary resources. That will enable a comparison of the most important life history parameters between the specimens reared in the laboratory and those from the field.

\section{Materials and methods}

\section{Insects}

$X$. arvicola adults were collected in 2005 from infested grape wood brought to the laboratory from 22 different grape fields located in Cigales (Valladolid, Spain). The wood was placed into plastic containers measuring $55 \times 40 \times 35 \mathrm{~cm}$ (length $\times$ breadth $\times$ height) at $24 \pm 1^{\circ} \mathrm{C}, 60 \pm 5 \% \mathrm{RH}$ and for a photoperiod of L16:D8. Recently emerged adults were paired (one male and one female) after sex identification based on the colour of femurs (Moreno, 2005) in 12-cm diameter plastic cylindrical cages with a perforated lid covered with a fine mesh. Cage bottoms were covered with filter paper. A piece of cotton impregnated with a $10 \%$ honey solution as a food source and a laying substrate consisting of $13 \times 4 \mathrm{~cm}$ (length $\times$ breadth) rolled paper were also added to the cage. These adult mating cages were maintained in a growth chamber (Sanyo MLR-350H, Sanyo, Japan) at $24 \pm 1{ }^{\circ} \mathrm{C}, 60 \pm 5 \%$ $\mathrm{RH}$ and for a photoperiod of L16:D8. If a male died, another was added to the cage to allow the female to continue laying eggs. Cages were checked daily, and the eggs obtained from the laying substrates were isolated in Petri dishes $(55 \mathrm{~mm}$ in diameter by $14 \mathrm{~mm}$ in height), which were covered with aluminium foil and maintained in a growth chamber at $24 \pm 1^{\circ} \mathrm{C}, 60 \pm 5 \% \mathrm{RH}$ until eggs hatched.

\section{Diet-rearing}

Four different diets were evaluated (table 1). Two, SSI (semi-synthetic Iglesias) and SI (synthetic Iglesias), were proposed by Iglesias et al. (1989) to rear eight different cerambycid species collected from maritime pine stumps (Pinus pinaster Aiton) in Madrid (Spain). Rogers et al. (2002) used the R (Rogers) diet to rear the cerambycid Prionoplus reticularis (White), while the RM (Rogers Modified) is a modification of the latter.

Dry yeast, ascorbic acid and nipagin were common to all diets. Dry yeast is an important source of micro- and macronutrients for some insect species (Tsitsipis, 1989), ascorbic acid is a growth factor required for adequate insect development (Chippendale \& Beck, 1965) and nipagin (methyl paraben) is an antifungal component.

Another source of nutrients for insects was corn meal present in SSI and RM diets. Oak sawdust was added to all diets, except the SI diet, as a growth promoter that stimulates eating (Dubois et al., 2002). Other growth promoters added to the diets, except the SSI diet, were cellulose, glucose, sucrose and casein. The mineral content was supplied by adding Wesson salts, except the SSI diet, and wheat germ, except the SI diet. The vitamin mixture in the SI, R and RM diets and L-methionin, present in the SI diet, are antioxidant agents. Sorbic (R and RM diets) or benzoic acid (SSI and SI diets) were added to the diets to inhibit the growth of yeasts, bacteria and fungus, while fumagilin, in the RM diet, is an antibiotic against protozoa.

For diets preparation purposes, sawdust, cellulose, dry yeast, cornmeal and wheat germ were sterilised, if needed, in an autoclave at $120^{\circ} \mathrm{C}$ for $20 \mathrm{~min}$. The antifungal nipagin solution was prepared by adding nipagin and benzoic acid to ethanol. Benzoic acid was substituted for sorbic acid in the $\mathrm{R}$ and $\mathrm{RM}$ diets. In a graduated two-litre glass jar, distilled water, agar and the previous nipagin solution were homogenised and heated to boiling point (about six min). When the temperature was below $60^{\circ} \mathrm{C}$ again, ascorbic acid and, if required, the vitamin solution were added together with the rest of the respective diet components and homogenised. Once cold, diets were kept in rectangular plastic containers $(227 \times 167 \times 30 \mathrm{~mm})$ at $4 \pm 1^{\circ} \mathrm{C}$. 
Table 1. Ingredients of the Iglesias' semi-synthetic (SSI), Iglesias' synthetic (SI), Rogers' (R) and Rogers' modified (RM) artificial diets for rearing $X$. arvicola.

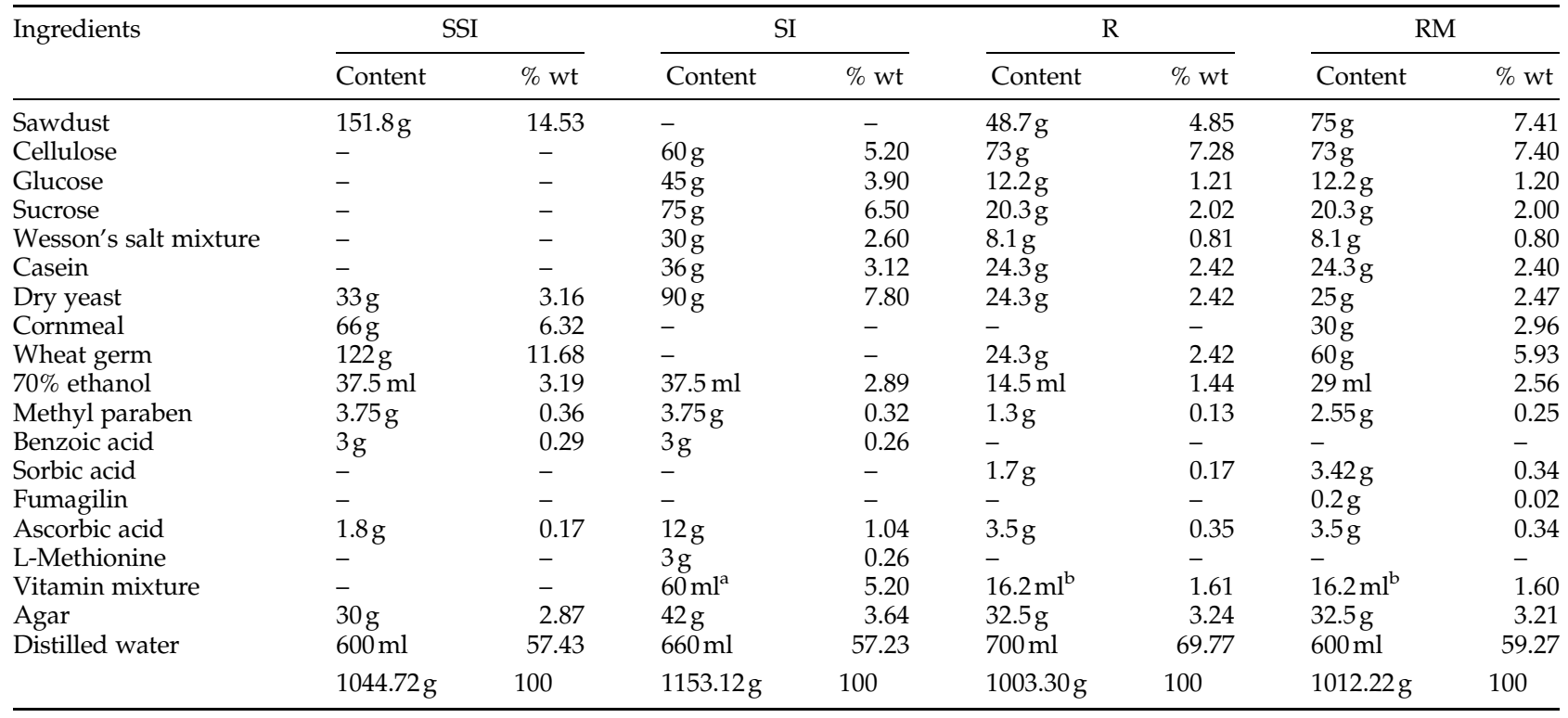

a Referred to as the vitamin mixture in Gardiner (1970).

b Referred to as the vitamin mixture in Rogers et al. (2002).

\section{Bioassays}

For the evaluation of each diet, 70 recently emerged larvae were used, except for the SSI diet for which 140 larvae were tested. Plastic cylindrical cages (30-mm diameter and 15-mm high) filled with the respectively tested diet were used. Neonate larvae $(<24 \mathrm{~h})$ were transferred daily to the diet cage with the help of a fine camel hair brush. Larvae were kept individually to prevent cannibalism. In each cage, a piece of 30-mm diameter paper was also placed over the larva and the diet to retain excess humidity and to recreate the natural conditions under the bark. These papers were removed after a week. Cages were maintained in a growth chamber in complete darkness at $24 \pm 1^{\circ} \mathrm{C}, 60 \pm 5 \% \mathrm{RH}$.

One month later, developed larvae were transferred to plastic cylindrical containers $(45-\mathrm{mm}$ diameter and 65-mm high) filled with the same diet to half their capacity, and the cages were kept under the same environmental conditions. The diet in these cages was changed monthly to avoid diet contamination and desiccation. Cages were checked twice per week and excess humidity was removed by cleaning it with absorbent paper. About nine months later, the larvae stopped eating. As proposed by many other authors, diapausing larvae were kept 45 days inside a cold chamber at $8 \pm 1^{\circ} \mathrm{C}$ in complete darkness to break the diapause (Dubois et al., 2002; Hodková \& Hodek, 2004; Keena, 2005). Larvae were then transferred to containers with fresh diet under the same conditions they had before the cold treatment, and they started to pupate about one month later. Sex identification was performed after the complete formation, esclerotisation and melanisation of adults. Once the fatty abdominal reserves are reabsorbed, it is possible to distinguish body colours between males and females (Moreno, 2005). Mortality and developmental time of each stage (the amount of time that an individual was a larva, a prepupa and a pupa) were recorded throughout the process. Once the pupae were completely formed they were weighted.
The adult females originating from the larvae reared on an artificial diet were then paired with males from the field population in the same plastic cylindrical cages described above and were maintained under the same temperature, humidity and photoperiod conditions. If a male died, another was added to the cage to allow the female to continue laying eggs. Cages were checked daily until the last female died, and females' daily fecundity and longevity were annotated. Fertility was determined by placing daily laid egg batches under the same conditions as previously described. Data were compared with those obtained with the adult females emerging from infested grape wood, and they were kept under the same mating conditions.

\section{Life table}

Life tables from beetles reared on diet were constructed using the daily number of eggs laid, the pre-laying period and adult female mortality. Additionally, the mean developmental time to adult, immature mortality and the sex ratio of the larvae reared on the SSI diet were considered. Several life history parameters were calculated: (i) the intrinsic rate of increase $\left(r_{\mathrm{m}}\right)$, which is the constant that appears in the differential equation that describes population increases in a confined environment, $\mathrm{d} N / \mathrm{d} t=r_{\mathrm{m}} t$, where $N$ is the number of individuals, $t$ is time and $r_{\mathrm{m}}$ is the intrinsic rate of increase; (ii) the finite rate of increase $(\lambda)$ that represents "the number of times a population with a stable age distribution multiplies in a time unit" (Birch, 1948), which is calculated as $\lambda=\mathrm{e}^{r \mathrm{~m}}$; (iii) the net reproduction rate $\left(R_{0}\right)$, which is defined as "the number of times a population multiplies in a generation" (Laughlin, 1965) and is calculated from the expression $0<R_{0}=\Sigma 1_{x} \mathrm{~m}_{\mathrm{x}}<\infty$, where $l_{x}$ is the 'age specific survivorship' or the number of living individuals at age $\times$ (days), and $\mathrm{m}_{\mathrm{x}}$ is the 'age specific fecundity' or the mean number of females produced in a time 
unit (day) by a female at age $\times$ (days); the mean duration of a generation $(T)$ is defined as the time from the birth of a generation to the mean birthdate of all its progenies, which is calculated with the expression: $T=\ln R_{0} / r_{\mathrm{m}}$; and (iv) the duplication time $(D T)$, which is the time necessary for a population to double its number of individuals, calculated with the expression $D T=\ln 2 / r_{\mathrm{m}}$.

\section{Statistics}

Immature developmental times and pupal weight from beetles reared on diet and adult biological parameters of females obtained from the SSI diet and emerged from infested grape wood were analysed using PROC ANOVA, and the mean comparisons by sex for immature developmental times and pupal weight and between populations for adult female biological parameters were made by a Duncan multiple range test $(P<0.05)$ (SAS Institute, 2003). Fitting the regression lines to adult survivorship (see fig. 2) and the associated parameter assessment were conducted with the help of the TableCurve 2D program (Jandel Scientific, 1994). The Kaplan-Meier survivorship analysis was performed to compare the adult female survivorship of the tested specimens from SSI diet and from infested grape wood, while survivorship distributions were compared by the Mantel log-rank test (SAS Institute, 2003). After determining the pre-laying period, the prereproductive survivorship, the age specific survivorship $\left(l_{x}\right)$ and the age specific fecundity $\left(\mathrm{m}_{\mathrm{x}}\right)$, the different population parameters were calculated with the $r_{\mathrm{m}} 2.0$ program (Taberner et al., 1993). For the variance estimations of the intrinsic rate of increase and its confidence intervals at 95\%, the Bootstrap technique was followed with 1000 replications, as suggested by Meyer et al. (1986).

\section{Results}

\section{Development of $\mathrm{X}$. arvicola on diets}

The mean embryonic developmental time from oviposition to egg hatch was previously calculated for 115 recently laid eggs at $24^{\circ} \mathrm{C}$ and complete darkness. It was $8.02 \pm 0.02$ days, with an egg survivorship of $73.04 \%$. Among the four tested diets, only the SSI diet enabled the rearing of X. arvicola, with larva-to-adult survivorship percentages of $36 \%$ (table 2). No survivors to the pupal stage were obtained when the larvae were reared on the SI or the R diet, and only one larva reached the adult stage on the RM diet. The highest larval mortality was recorded during the first two larval instars because many larvae did not accept the diet and could not dig into it. The prepupa, a 5-6-day transition stage between the larva and the pupa, and the pupa presented mortalities of $10 \%$ and $12 \%$, respectively. The cumulative egg-to-adult survivorship for the SSI diet was $26 \%$.

The sex ratio (females/total) for the SSI diet was 0.54, indicating a similar male and female emergence to that obtained for the adults emerging from infested grape wood (0.47). The only individual to emerge from the RM diet was male (table 2). Significant differences between males and females from the SSI diet-reared larvae were found in neither the larval $(\mathrm{F}=0.42 ; \mathrm{df}=1,49 ; P=0.52)$ and prepupal $(\mathrm{F}=1.97$; $\mathrm{df}=1,49 ; P=0.17$ ) developmental times, nor the total larva to the adult developmental time $(\mathrm{F}=0.32 ; \mathrm{df}=1,49 ; P=0.57)$ (table 3). However, female pupal developmental time was significantly longer than for males $(\mathrm{F}=9.39 ; \mathrm{df}=1,49 ; P<0.01)$.
Table 2. Survivorship and developmental time of the immature stages of $X$. arvicola reared on four different diets.

\begin{tabular}{|c|c|c|c|c|c|}
\hline \multirow[t]{2}{*}{ Stage } & \multirow[t]{2}{*}{ Parameter $^{\mathrm{b}}$} & \multicolumn{4}{|c|}{$\operatorname{Diet}^{a}$} \\
\hline & & SSI & SI & $\mathrm{R}$ & $\mathrm{RM}$ \\
\hline \multirow[t]{3}{*}{ Larva } & No. & 140 & 70 & 70 & 70 \\
\hline & \% Survivorship & 44.29 & 0 & 0 & 1.43 \\
\hline & $T$ (days) & $296.13 \pm 7.62$ & - & - & 246 \\
\hline \multirow[t]{3}{*}{ Prepupa } & No. & 62 & - & - & 1 \\
\hline & \% Survivorship & 90.32 & - & - & 100 \\
\hline & $T$ (days) & $5.45 \pm 0.20$ & - & - & 4 \\
\hline \multirow[t]{3}{*}{ Pupa } & No. & 56 & - & - & 1 \\
\hline & \% Survivorship & 89.29 & - & - & 100 \\
\hline & $T$ (days) & $17.48 \pm 0.34$ & - & - & 19 \\
\hline \multirow[t]{3}{*}{ Larva-adult } & No. & 50 & - & - & 1 \\
\hline & \% Survivorship & 35.71 & - & - & 1.43 \\
\hline & $T$ (days) & $321.96 \pm 8.59$ & - & - & 269 \\
\hline Egg-adult & $\%$ Survivorship & 26.09 & - & - & 1.04 \\
\hline
\end{tabular}

a SSI, semi-synthetic Iglesias rearing diet; SI, Synthetic Iglesias rearing diet; $\mathrm{R}$, Rogers rearing diet; $\mathrm{RM}$, Rogers modified rearing diet.

${ }^{b}$ No., number of individuals; $T$ (days): Developmental time $( \pm S E)$ of each stage in days.

- , no data available.

The mean female pupal weight was also significantly greater $(\mathrm{F}=6.81 ; \mathrm{df}=1,49 ; P=0.01)$.

\section{Adult biological parameters}

The biological parameters of adult females obtained from the SSI diet were compared with those obtained from the adults emerging from infested grape wood, maintained under the same climatic conditions (table 4). Although not statistically different, females from the SSI rearing diet laid more eggs $(244 \pm 37$ eggs per female) than those emerging from grape wood $(196 \pm 13$ eggs per female) $(\mathrm{F}=2.55 ; \mathrm{df}=1,71 ; P=0.11)$. No significant differences were either observed in the prelaying period (about one day, $\mathrm{F}=1.25 ; \mathrm{df}=1,71 ; P=0.27$ ), in fertility (about $70 \%, \mathrm{~F}=0.27 ; \mathrm{df}=1,71 ; P=0.82$ ) or in the greatest number of eggs laid on one day (about 46 eggs per female, $\mathrm{F}=0.00 ; \mathrm{df}=1,71 ; P=0.99$ ). In contrast, the females obtained from the rearing SSI diet lived significantly longer $(37 \pm 4$ days) than those emerging from infested wood ( $24 \pm 2$ days $)(\mathrm{F}=14.65 ; \mathrm{df}=1,71 ; P<0.01)$ and showed a longer post-laying period $(\mathrm{F}=24.37 ; \mathrm{df}=1,71 ; P<0.01)$. The mean laying period was significantly longer for the females reared on the SSI diet ( $26 \pm 3$ days) than for those emerging from infested wood ( $19 \pm 1$ days) $(\mathrm{F}=4.58 ; \mathrm{df}=1,71 ; P=0.03)$. In both cases, females laid eggs for almost $70 \%$ of their mean whole life span. Females reared on the SSI artificial diet laid the greatest number of eggs in a day significantly later than females emerging from infested grape $\operatorname{wood}(\mathrm{F}=5.89 ; \mathrm{df}=1$, $71 ; P=0.02)$.

Mean fecundity in both the females reared on the SSI artificial diet and those emerging from infested grape wood revealed a clearly asymmetric model (fig. 1). Cumulative fecundity (percentage of total eggs deposited by females at a specific age) was greater than $50 \%$ at the end of the first week, and greater than $75 \%$ at the end of the second week.

Percentage survivorship (fig. 2) of the females emerging from infested grape wood (field) was above $80 \%$ in the first two weeks but progressively decreased thereafter. No female 
Table 3. Sex-differentiated developmental time $( \pm \mathrm{SE})$ of the immature stages and pupal weight $( \pm \mathrm{SE})$ of the $X$. arvicola reared on the semi-synthetic Iglesias rearing diet (SSI).

\begin{tabular}{|c|c|c|c|c|c|}
\hline \multirow[t]{2}{*}{$\operatorname{Sex}^{\mathrm{a}}$} & \multicolumn{4}{|c|}{ Developmental time (days) } & \multirow[t]{2}{*}{ Pupal wt (mg) } \\
\hline & Larva & Prepupa & Pupa & Larva-adult & \\
\hline Male (23) & $305.04 \pm 13.92 \mathrm{a}$ & $5.78 \pm 0.34 a$ & $16.43 \pm 0.49 a$ & $327.26 \pm 14.10 \mathrm{a}$ & $399.13 \pm 26.80 a$ \\
\hline
\end{tabular}

The means within a column followed by the same letters are not significantly different $(P<0.05$; Duncan test).

${ }^{a}$ In brackets, the number of individuals.

Table 4. Mean biological parameter values $( \pm$ SE) of the adult females of $X$. arvicola from infested grape wood (field) and laboratory rearing on semi-synthetic Iglesias (SSI) artificial diet (reared).

\begin{tabular}{lcc}
\hline Parameter & Field & Reared \\
\hline No. of females & 45 & 27 \\
Fecundity (eggs per female) & $196.22 \pm 12.51 \mathrm{a}$ & $244.42 \pm 36.69 \mathrm{a}$ \\
Longevity (days) & $23.64 \pm 1.55 \mathrm{a}$ & $37.42 \pm 4.19 \mathrm{~b}$ \\
Laying period (days) & $19.38 \pm 1.34 \mathrm{a}$ & $25.79 \pm 3.32 \mathrm{~b}$ \\
Pre-laying period (days) & $1.11 \pm 0.16 \mathrm{a}$ & $1.68 \pm 0.75 \mathrm{a}$ \\
Post-laying period (days) & $3.15 \pm 0.69 \mathrm{a}$ & $9.95 \pm 2.26 \mathrm{~b}$ \\
Day of greatest egg-laying & $4.29 \pm 0.40 \mathrm{a}$ & $7.47 \pm 1.92 \mathrm{~b}$ \\
$\quad$ (days) & & \\
Greatest egg-laying on one day & $46.13 \pm 4.19 \mathrm{a}$ & $46.21 \pm 6.80 \mathrm{a}$ \\
$\quad$ (eggs per female) & & \\
Fertility (\%) & $69.03 \pm 3.30 \mathrm{a}$ & $74.00 \pm 4.66 \mathrm{a}$ \\
\hline
\end{tabular}

The means within a row followed by the same letters are not significantly different $(P<0.05$; Duncan test).

lived longer than 50 days. Female survivorship fitted a linear model $\left(\mathrm{F}=2,253.88 ; \mathrm{df}=1 ; \mathrm{R}_{\mathrm{a}}^{2}=0.98\right.$; ordinate $=107.47$; slope $=-2.36)$. More than $90 \%$ of the females from individuals reared on the SSI diet survived the two first weeks, and about $60 \%$ survived 30 days. Approximately $10 \%$ of females lived longer than 60 days. Female survivorship also fitted a linear model $\left(\mathrm{F}=2,245.22 ; \mathrm{df}=1 ; \mathrm{R}_{\mathrm{a}}^{2}=0.97\right.$; ordinate $=110.10$; slope $=$ -1.54). Females from individuals reared on the SSI diet lived significantly longer than females from infested grape wood (Log-Rank test; $X^{2}=8.77, P<0.01$ ).

\section{Life table}

The life table parameters obtained for those individuals reared in the laboratory on the semi-synthetic Iglesias (SSI) diet are summarised in table 5 . Each female produced about 34 females, as $R_{0}$ indicates. The mean duration of a generation (T) was almost one year (342 days), and the population increased daily by $1.01(\lambda)$, multiplying itself 1.01 times on one day. Every 67 days $(D T)$, population individuals doubled in number and the intrinsic rate of increase for $X$. arvicola was about 0.01 .

\section{Discussion}

$X$. arvicola could not complete its total larva-to-adult development on any of the tested diets other than SSI diet, with a survivorship of $36 \%$. The other diets were not appropriate in quality as far as texture, consistency, humidity and nutrient content are concerned in order to rear this species under laboratory conditions. The methodological complexity and the low larval survivorship already reported by other authors for some species of the same family were the causes hindering the species from being reared in the laboratory. In a previous work, Moreno (2005) could not rear X. arvicola from neonate larvae to adult, and pointed out that neonate larval mortality was the most important constraint to rearing this species in the laboratory. Likewise, a high larval mortality has been reported for many other cerambycid species, such as Xylotrechus quadripes (Chevrolat) with a 25\% larva-to-adult survivorship (Visitpanich, 1994), Acalolepta vastator (Newman) presenting a 34\% larval survivorship (Goodwin \& Pettit, 1994) or Phoracantha semipunctata F with a mean larva-to-adult survivorship of 35\% (Hanks et al., 1993). Nevertheless, for two species of the same genus, Phoracantha recurva (Newman) and P. semipunctata, Bybee et al. (2004) reported larva-to-adult survivorship percentages of $70 \%$ and 64\%, respectively, while Galford (1985) was able to rear Enaphalodes rufulus (Haldeman) by obtaining an egg-to-adult survivorship of $87 \%$. Low survivorship on the SSI diet and in the examples presented below indicates that more work needs to be done to refine this diet.

The critical phase for the laboratory rearing of these species appears to be acceptance of diet during the first larval instar, as indicated by Lee \& Lo (1998) for Anoplophora macularia (Thomson). They confirmed that the reason for this species' high larval mortality was that many neonate larvae did not accept the diet and that those that did could actually complete their development in the normal manner. Moreover, Kosaka \& Ogura (1990) with Monochamus alternatus (Hope) observed that the neonate larvae, which did not accept the diet in the first few hours after being transferred to it, died during the first larval instars.

Some authors considered the addition of some host plant components to diet, particularly sawdust, to stimulate feeding and as a growing promoter (Necibi \& Linit, 1997). Thus, Kosaka \& Ogura (1990) showed that pupae weight and survivorship increased when a larger quantity of plant-specific component was added to the diet, while others recommended it because increasing sawdust increases the probability that neonate larvae will feed on an artificial diet (Gardiner, 1970). However, Lee \& Lo (1998) verified that a larger amount of sawdust of the host species in the diet did not seem to increase the larval survivorship of $A$. macularia in laboratory rearing, and the same occurred with the larvae of Prionus imbricornis L. (Payne et al., 1975). Our results support the importance of adding sawdust to the diet for rearing $X$. arvicola since this species could complete its larva-to-adult development in the laboratory only on the diet with a significant amount of this component.

The SSI diet is not the only one to contain more sawdust, but it contains fewer ingredients. Continuous rearing of 


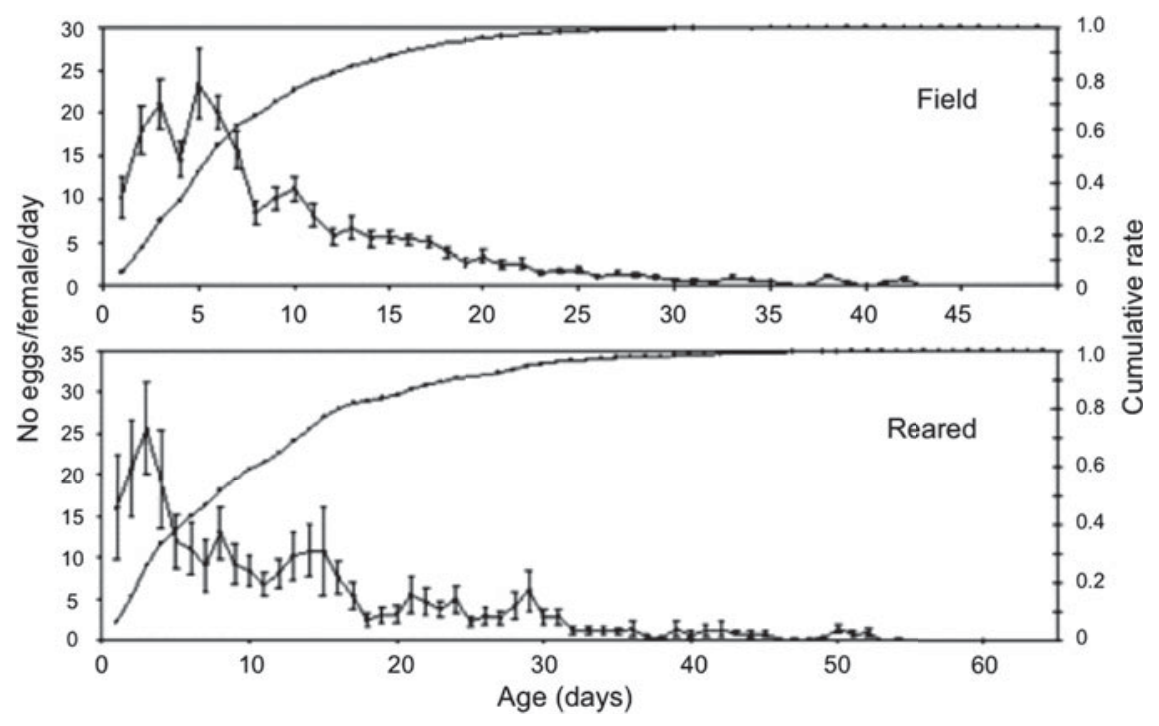

Fig. 1. Mean and cumulative fecundity $( \pm \mathrm{SE})$ of the females of X. arvicola emerging from infested grape wood (field) and reared on the semisynthetic Iglesias (SSI) artificial diet (reared).

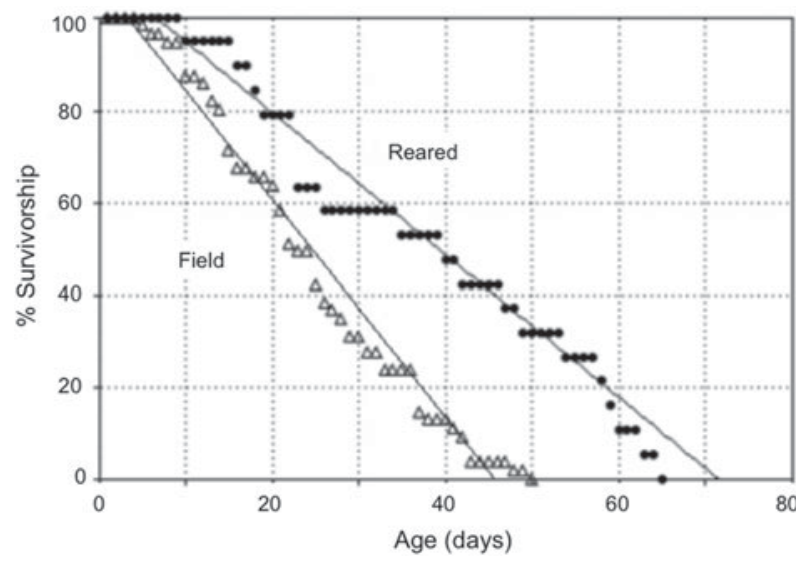

Fig. 2. Observed survivorship values of the females of $X$. arvicola emerging from infested grape wood (field) $(\Delta)$ and reared on the semi-synthetic Iglesias (SSI) artificial diet (reared) $(\bullet)$.

$X$. arvicola in the laboratory has demonstrated that the SSI diet supplies larvae's nutritional requirements and helps rear the species easily. The diet remains free of microorganisms for more than a month, maintains its texture and consistency, thus minimising larval mortality risks as a result of excess handling. It is subsequently possible to reduce the quantity of antimicrobial components to reduce the potential deleterious effects caused by these components given their insecticidal activity (Singh, 1983). This appears to be the direction to follow to improve diet in the future.

Rearing cerambycids in the laboratory has already been seen to shorten life cycle duration in relation to the field (Gardiner, 1970; Galford, 1985). Thus, the life cycle of $X$. arvicola (two years in the field) has been reduced to half its length when reared in the laboratory ( $332 \pm 9$ days). As reported by other authors (Shintani \& Ishikawa, 1997; Dubois et al., 2002; Rogers et al., 2002) and as corroborated by our
Table 5. Life table parameters of $X$. arvicola reared in the laboratory on the semi-synthetic Iglesias (SSI) artificial diet at $24 \pm 1^{\circ} \mathrm{C}, 60 \pm 5 \% \mathrm{RH}$ and 16:8 (L:D).

Parameter

\begin{tabular}{lc}
\hline Net reproduction rate $\left(R_{0}\right)$ & 34.45 \\
Mean duration of a generation $(T)$ (days) & 341.83 \\
Intrinsic rate of increase $( \pm \mathrm{SE})\left(r_{\mathrm{m}}\right)$ & $0.0104 \pm 0.0004$ \\
$r_{\mathrm{m}}$ confidence interval 95\% & $0.0095-0.0112$ \\
Finite rate of increase $(\lambda)$ & 1.01 \\
Duplication time $(D T)$ (days) & 66.65 \\
Egg-to-adult survivorship $(\%)$ & 26.09 \\
\hline
\end{tabular}

results, a chilling period of variable duration (45 days in this case), during the last larval instars, effectively terminates the larval diapause and shortens development time; but this matter requires further study.

The females born of those individuals reared in the laboratory have a significantly longer mean pupal developmental time, and they weigh significantly more than males. Similar results have been reported for other cerambycid species like Acalolepta vastator (Newman) (Goodwin \& Pettit, 1994), Anoplophora glabripennis (Motschulsky) (Dubois et al., 2002) or Oemona hirta F. (Wang et al., 2002). More importantly, a positive relationship between pupal weight and fecundity has been demonstrated for cerambycid species (Jikumaru et al., 1994; Smith et al., 2002; Wang et al., 2002). Our results reveal that the fecundity of those females born to individuals reared on the SSI diet is greater ( 244 eggs per female) than for the females emerging from infested grape wood (197 eggs per female). This suggests that the SSI diet satisfies larvae nutritional requirements. The fecundity values obtained from $X$. arvicola are higher than those shown for other species of the same subfamily, such as X. quadripes (103 eggs per female) (Visitpanich, 1994), Aeolesthes sarta (Solsky) (123 eggs per female) (Mazaheri et al., 2007) and E. rufulus (80 eggs per female) (Galford, 1985). Our fecundity and longevity results are also better than those offered by Moreno (2005) for 
$X$. arvicola, who reported a daily fecundity of between one and 20 eggs per female and a mean longevity of 16 days (with a range of 11-30 days). Thus, the females of this species lay more viable eggs and over a longer time than originally thought.

Cerambycids that feed during the adult stage generally live between one and two months, depending on the sex and the rearing method employed (Hanks, 1999), although longer life spans have been documented for species of the subfamily Lamiinae (Linsley, 1959), with adults of A. glabripennis, for example, living up to 112 days (Keena, 2005). Individuals of the subfamily Cerambycinae, to which $X$. arvicola belongs, have shown life spans that vary between 21 days for the adults of E. rufulus (Galford, 1985) and 29 days for the adults of $X$. quadripes (Visitpanich, 1994). The longevity obtained for the females of $X$. arvicola emerging from infested plant material ( $24 \pm 2$ days) is highly similar to that reported for other species in the same subfamily. In contrast, the longevity ( $37 \pm 4$ days) and laying period of the females obtained from individuals reared on diet are significantly longer.

Knowing the distribution of eggs laid over the entire life of a female of $X$. arvicola is very important in order to design the control strategies against this pest in the field because colonisation and damage levels depend on dispersal and reproduction ratios (Myers et al., 2000). The mean pre-laying period was very short (less than two days), and no significant differences were found between the females from infested wood and those reared on the diet. Hanks (1999) established a mean feeding period before mating of almost seven days for 21 species of the subfamily Lamiinae, while in the subfamily Cerambycinae, the pre-laying time was eight and four days for E. rufulus (Galford, 1985) and A. sarta (Mazaheri et al., 2007), respectively. The laying behaviour of $X$. arvicola resembles that described by Visitpanich (1994), who stated how the majority of eggs of $X$. quadripes are laid by females during their first week of life and how the fourth day was the day on which mean female fecundity was greater. Adult females of $X$. arvicola laid $65 \%$ (for those following the diet) and $80 \%$ (for those from infested wood) of the eggs laid in the first ten days after their emergence.

Specific survivorship, fecundity and egg viability are the main factors affecting the reproductive success of a given species because they have a huge impact on the intrinsic rate of increase $\left(r_{\mathrm{m}}\right)$. Akbulut \& Linit (1999) reported values of $r_{\mathrm{m}}$ for Monochamus carolinensis (Olivier) of 0.04 to 0.13 on pinewood and Mazaheri et al. (2007) of 0.0067 for A. sarta, which are very similar to the values of 0.01 obtained for $X$. arvicola in this work. Low $r_{\mathrm{m}}$ values are the result of long developmental times (322 days) and high larval mortality (55\%) and, to a lesser extent, are caused by a shorter adult life span than other species of the same family. Despite all this, $R_{0}$ of $X$. arvicola is near 34.5 ; consequently, it can be considered a species with moderate expansion ability (Powell, 1982). The data presented in this work not only highlight the potential of this species to become a problem for many wine growers in the near future, but can also help towards the application of specific control strategies after adults have emerged. Thus, these results should merely promote more exhaustive field- and diet-based laboratory studies to clarify other important aspects of this species' biology and ecology, which could be applied to develop more effective control tools to be incorporated into this species' management program.

\section{Acknowledgements}

We are thankful to Dr F. Ortego for critically reviewing the manuscript. This research work has been funded by the Spanish Institute for Food and Agricultural Sciences and Technologies (INIA), project No. RTA04-117-C2.

\section{References}

Adachi, I. (1988) Reproductive biology of the white-spotted longicorn beetle, Anoplophora malasiaca Thomson (Coleoptera: Cerambycidae), in citrus trees. Applied Entomology and Zoology 23, 256-264.

Akbulut, S. \& Linit, M.J. (1999) Seasonal effect on reproductive performance of Monochamus carolinensis (Coleoptera: Cerambycidae) reared in pine logs. Journal of Economic Entomology 92, 631-637.

Birch, L.C. (1948) The intrinsic rate of natural increase of an insect population. Journal of Animal Ecology 17, 15-26.

Bybee, L.F., Millar, J.G., Paine, T.D., Campbell, K. \& Hanlon, C.C. (2004) Seasonal development of Phoracantha recurva and $P$. semipunctata (Coleoptera: Cerambycidae) in Southern California. Environmental Entomology 33, 1232-1241.

Chippendale, G.M. \& Beck, S.D. (1965) A method for rearing the cabbage looper, Trichoplusia ni, on a meridic diet. Journal of Economic Entomology 58, 377-378.

Cornell, H.V. \& Hawkins, B.A. (1995) Survival patterns and mortality sources of herbivorous insects: some demographic trends. American Naturalist 145, 563-593.

Dubois, T., Hajek, A.E. \& Smith, S. (2002) Methods for rearing the Asian longhorned beetle (Coleoptera: Cerambycidae) on artificial diet. Annals of the Entomological Society of America 95, 223-230.

Galford, J.R. (1985) Enaphalodes rufulus. pp. 255-264 in Singh, P. \& Moore, R.F. (Eds) Handbook of Insect Rearing, vol. I. New York, USA, Elsevier.

Gardiner, L.M. (1970) Rearing wood-boring beetles (Cerambycidae) on artificial diet. Canadian Entomologist 102, 113-117.

Goodwin, S. \& Pettit, M.A. (1994) Acalolepta vastator (Newman) (Coleoptera: Cerambycidae) infesting grapevines in the Hunter Valley, New South Wales: biology and ecology. Australian Journal of Entomology 33, 391-397.

Hanks, L.M. (1999) Influence of the larval host plant on reproductive strategies of cerambycid beetles. Annual Review of Entomology 44, 483-505.

Hanks, L.M., McElfresh, J.S., Millar, J.G. \& Paine, T.D. (1993) Phoracantha semipunctata (Coleoptera: Cerambycidae), a serious pest of eucalyptus in California: biology and laboratory-rearing procedures. Annals of the Entomological Society of America 86, 96-102.

Harcourt, D.G. (1969) The development and use of life tables in the study of natural insect populations. Annual Review of Entomology 14, 175-191.

Hodková, M. \& Hodek, I. (2004) Photoperiod, diapause and coldhardiness. European Journal of Entomology 101, 445-458.

Iglesias, C., Notario, A. \& Baragaño, J.R. (1989) Evaluación de las condiciones de cría y datos bionómicos de coleópteros lignícolas de tocón de pino. Boletín de Sanidad Vegetal. Plagas 15, 9-16.

Jandel Scientific (1994) TableCurve user's manual. San Rafael, CA, USA, Jandel Scientific.

Jikumaru, S., Togashi, K., Taketsune, A. \& Takahashi, F. (1994) Oviposition biology of Monochamus saltuarius 
(Coleoptera: Cerambycidae) at a constant temperature. Applied Entomology and Zoology 29, 555-561.

Keena, M.A. (2005) Pourable artificial diet for rearing Anoplophora glabripennis (Coleoptera: Cerambycidae) and methods to optimize larval survival and synchronize development. Annals of the Entomological Society of America 98, 536-547.

Kosaka, H. \& Ogura, N. (1990) Rearing of the Japanese pine sawyer, Monochamus alternatus (Coleoptera: Cerambycidae) on artificial diets. Applied Entomology and Zoology 25, 532-534.

Laughlin, R. (1965) Capacity for increase: a useful population statistic. Journal of Animal Ecology 34, 77-91.

Lee, C.Y. \& Lo, K.C. (1998) Rearing of Anoplophora macularia (Thomson) (Coleoptera: Cerambycidae) on artificial diets. Applied Entomology and Zoology 33, 105-109.

Linit, M.J. (1985) Continuous laboratory culture of Monochamus carolinensis (Coleoptera: Cerambycidae) with notes on larval development. Annals of the Entomological Society of America 78, 212-213.

Linsley, E.G. (1959) Ecology of Cerambycidae. Annual Review of Entomology 4, 99-138.

Mazaheri, A., Hatami, B., Khajehali, J. \& Sadeghi, E. (2007) Reproductive parameters of Aeolesthes sarta Solsky (Col.: Cerambycidae) on Ulmus carpinifolia Borkh. under laboratory conditions. Journal of Science and Technology of Agriculture and Natural Resources 11, 333-343.

Myers, J.H., Simberloff, D., Kuris, A.M. \& Carey, J.R. (2000) Eradication of exotic species - A reply. Trends in Ecology $\mathcal{E}$ Evolution 15, 516-517.

Meyer, J.S., Ingersoll, C.G., McDonald, L.L. \& Boyce, M.S. (1986) Estimating uncertainty in population growth rates: jackknife vs. bootstrap techniques. Ecology 67, 1156-1166.

Moreno, C.M. (2005) Xylotrechus arvicola (Olivier, 1795) (Coleoptera: Cerambycidae): descripción morfológica, ciclo biológico, incidencia y daños en el cultivo de la vid. $\mathrm{PhD}$ thesis, Instituto Tecnológico Agrario de Castilla y León, Valladolid, Spain.

Naranjo, S.E. \& Ellsworth, P.C. (2005) Mortality dynamics and population regulation in Bemisia tabaci. Entomologia Experimentalis et Applicata 116, 93-108.

Necibi, S. \& Linit, M. (1997) A new artificial diet for rearing Monochamus carolinensis (Coleoptera: Cerambycidae). Journal of the Kansas Entomological Society 70, 145-146.

Ocete, R. \& Del Tío, R. (1996) Presencia del perforador Xylotrechus arvicola (Olivier) (Coleoptera, Cerambycidae) en viñedos de la Rioja Alta. Boletín de Sanidad Vegetal. Plagas 22, 199-202.

Ocete, R., López-Martínez, M.A., Prendes, C., Lorenzo, C.D., González-Andújar, J.L. \& Lara, M. (2002) Xylotrechus arvicola (Oivier) (Coleoptera: Cerambycidae), a new impacting pest on Spanish vineyards. Vitis 41, 211-212.
Payne, J.A., Lowman, H. \& Pate, R.R. (1975) Artificial diets for rearing the tilehorned Prionus. Annals of the Entomological Society of America 68, 680-682.

Powell, W. (1982) Age-specific life-table data for the Eucalyptus boring beetle, Phoracantha semipunctata (F.) (Coleoptera: Cerambycidae), in Malawi. Bulletin of Entomological Research 72, 645-653.

Rogers, D.J., Lewthwaite, S.E. \& Dentener, P.R. (2002) Rearing huhu beetle larvae, Prionoplus reticularis (Coleoptera: Cerambycidae) on artificial diet. New Zealand Journal of Zoology 29, 303-310.

Rodríguez, M., Ocaña, P.J. \& Oliver, M. (1997) Presencia del perforador Xylotrechus arvicola (Olivier) en viñas de la provincia de Ciudad Real. pp. 102-104 in Proceedings of the XXII Reunión del Grupo de Trabajo de los Problemas Fitosanitarios de la Vid, Ciudad Real, 18-20 February 1997. Ciudad Real, Spain.

SAS Institute (2003) Version 9.1. Cary, NC, SAS Institute.

Shintani, Y. \& Ishikawa, Y. (1997) Effects of photoperiod and low temperature on diapause termination in the yellow-spotted longicorn beetle (Psacothea hilaris). Physiological Entomology 22, 170-174.

Singh, P. (1983) A general purpose laboratory diet mixture for rearing insects. Insect Science and Its Application 4, 357-362.

Smith, M.T., Bancroft, J. \& Trapp, J. (2002) Age-specific fecundity of Anoplophora glabripennis (Coleoptera: Cerambycidae) on three tree species infested in the United States. Environmental Entomology 31, 76-83.

Taberner, A., Castañera, P., Silvestre, E. \& Dopazo, J. (1993) Estimation of the intrinsic rate of natural increase and its error by both algebraic and resampling approaches. Computer Applications in the Bioscience 9, 535-540.

Toepfer, S. \& Kuhlmann, U. (2006) Constructing life-tables for the invasive maize pest Diabrotica virgifera virgifera (Coleoptera: Chrysomelidae) in Europe. Journal of Applied Entomology 103, 193-205.

Tsitsipis, J.A. (1989) Nutrition requirements. pp. 101-116 in Robinson, A.S. \& Hooper, G.H.S. (Eds) Fruit Flies: Their Biology, Natural Enemies and Control, vol. 3A. Amsterdam, Netherlands, Elsevier.

Villiers, A. (1978) Faune des Coléoptères de France, vol. I: Cerambycidae. Paris, France, Editions Lechevalier.

Visitpanich, J. (1994) The biology and survival rate of the coffee stem borer, Xylotrechus quadripes Chevrolat (Coleoptera: Cerambycidae). Japanese Journal of Entomology 62, 731-745.

Wang, Q., Shi, G.L., Song, D.P., Rogers, D.J., Davis, L.K. \& Chen, X. (2002) Development, survival, body weight, longevity, and reproductive potential of Oemona hirta (Coleoptera: Cerambycidae) under different rearing conditions. Journal of Economic Entomology 95, 563-569. 